Published as:

Bailey B.M., Leterrier Y., Garcia S.J., van der Zwaag S., Michaud V., Electrically Conductive SelfHealing Polymer Composite Coatings, Prog. Org. Coat., 85, 189-198 (2015). DOI 10.1016/j.porgcoat. 2015.04.013. (c) 2015. This manuscript version is made available under the CC-BY-NC-ND 4.0 license http://creativecommons.org/licenses/by-nc-nd/4.0/

\title{
Electrically Conductive Self-Healing Polymer Composite Coatings
}

\author{
Brennan M. Bailey ${ }^{1}$, Yves Leterrier ${ }^{1 *}$, S.J. Garcia ${ }^{2}$, S. van der Zwaag ${ }^{2}$ \\ and Véronique Michaud ${ }^{1}$ \\ ${ }^{1}$ Laboratoire de Technologie des Composites et Polymères (LTC), Ecole Polytechnique \\ Fédérale de Lausanne (EPFL), CH-1015 Lausanne, Switzerland \\ ${ }^{2}$ Novel Aerospace Materials, Department of Aerospace Engineering, Delft University of \\ Technology, 2629 HS, Delft, Netherlands \\ *E-mail: yves.leterrier@epfl.ch
}

\begin{abstract}
The goal of the research described herein is the fabrication and assessment of electrically conductive partially-cured epoxy coatings which, upon cracking, autonomously restore barrier, mechanical and electrical properties via a microcapsule based healing mechanism. Upon cracking, microcapsules in the crack path release the 'healing' solvent ethyl phenyl acetate (EPA), which locally swells the matrix, promoting crack closure and enabling the diffusion and subsequent reaction of the residual hardener in the vicinity of the crack. Two different self-healing coatings and two controls based on an electrically conductive epoxy resin with approximately $20 \%$ carbon nanotubes (CNTs) were fabricated. Electrochemical impedance spectroscopy was employed to evaluate the potential of the CNT and non-CNT containing encapsulated systems to restore relatively large cracks and thus restore the barrier function. An in-situ electro-tensile test in a microscope revealed that electrical conductivity and mechanical properties were restored to $64 \%( \pm 23)$ and $81 \%( \pm 39)$ respectively, which correlated to crack closure. Under appropriate testing conditions the system showed successive damage-heal events in terms of electrical conductivity.
\end{abstract}

Key Words: Self-healing; microcapsules; electrical conductivity; epoxy; coatings

\section{Introduction}

Microelectronic devices are used across all facets of life and industry. The push towards smaller devices with higher reliability provokes the need for failure assessment and subsequent repair of such devices. Inevitably, failure probabilities increase if devices are not consistently maintained and repaired [1-3]. For mass produced miniaturized electronic components, the high cost, difficulty, or even impossibility of repair justify research concerning materials capable of 'self-healing' upon the occurrence of damage [4-7]. Thus, the goal of this research is to fabricate materials commonly used in microelectronics possessing the ability to automatically recover their original functionality much like wound healing within a biological system [3, 8-11]. For such systems, the occurrence of local damage in the form of cracks would initiate the transport of new material to the site of failure. Subsequent restoration of the properties (i.e. healing) would occur as a result of the local chemical reaction in and near the crack.

Electrically conductive epoxies (ECAs) are often used as external coatings, 'bulk' packaging materials or as interconnects for electronic devices [12-16]. Thermoset epoxies are commonly chosen due to their relevant properties, such as excellent adhesive strength, good chemical and corrosion resistance, and low cost [6, 16-19]. Conductive fillers (e.g. silver, gold, nickel, copper, and carbon) provide the composite with electrical conductivity $[6,17]$. Carbon nanotubes (CNTs) are ideal as conductive fillers due to their excellent electrical 
conductivity, nanoscopic size, and high aspect ratio, which facilitate the formation of a network allowing for electron transport along the CNTs. In addition to sufficient electrical conductivity, ECAs based on epoxy and CNTs demonstrate improved adhesion and mechanical properties (including strength) compared to pristine epoxy [20-24]. However, even with the additional reinforcement resulting from CNTs, the epoxy matrix is still prone to cracking which often leads to device failure. In fact, depending on the CNT loading in the epoxy, the incorporation of CNTs can actually increase brittleness and, thus, likelihood of unforeseen cracking.

Many studies have demonstrated the possibility to convert brittle and inert epoxies into selfhealing systems via a microcapsule-based mechanism [25-29]. In a microcapsule-based system, the liquid healing agent is confined to small capsules, homogeneously dispersed within the polymer matrix. Upon matrix cracking, the embedded microcapsules near the matrix crack open and release their contents into the damaged site $[8,25,30]$. White et al. 'self-healed' bulk epoxy using microencapsulated dicyclopentadiene (DCPD) monomer and Grubbs' catalyst [25]. This method was later adapted to 'self-healing' of epoxy adhesive films commonly used in the aerospace and automotive industries for bonding metallic and composite substrates [31].

Caruso was first to report a solvent-based microcapsule self-healing system [32] which has since been adapted and utilized in many epoxy matrices [27, 33-35]. In such a system, healing only occurs if the epoxy matrix is left under-cured so that some residual hardener remains dormant in the film. In the case of cracking a microcapsule containing the 'healing' solvent ethyl phenyl acetate (EPA), diffusion of EPA in epoxy increases chain mobility and the matrix swells allowing gap closure and enabling the reaction of the residual hardener within the matrix. Thus the crack gap is decreased and cured (i.e. healed) [36]. Of course the limited volume of healing agent in the capsules limits the crack opening distance that can be healed [35], and the EPA healing agent in the capsule has a finite shelf life [34]. However, this system is a good model system that is neither toxic nor costly [27, 37, 38]. Caruso et al. explained and verified that additional epoxy delivered to the crack plane from the ruptured capsules improves the chance for additional crosslinking and helps bond new thermoset material to the original matrix interface [33]. In addition, Neuser et al. calculated that the additional epoxy should allow for the healing of slightly larger cracks [35]. Recently, microencapsulated suspensions of metal or carbon black were used to restore electrical conductivity in a multilayer microelectronic device and battery electrode respectively [39, 40]. However, reported healing in epoxy matrices thus far is limited to crack healing and recovery of mechanical properties without attention paid to electrical conductivity. When considering electrically conductive epoxies, restoration of electrical conductivity is equally, if not more, crucial for device success. Thus, the goal of this research is the inclusion of an electrically conductive epoxy/solvent-based microcapsule 'self-healing' system in an electrically conductive epoxy coating.

To this aim, two different self-healing coatings and two controls based on an electrically conductive epoxy resin with a high concentration ( 20\%) of CNTs were fabricated. The two self-healing coatings contained microcapsules filled with EPA and either epoxy with CNTs or without CNTs. These model systems allow for the evaluation of solvent-based microcapsule self-healing in electrically conductive coatings. Two methods were developed to assess selfhealing of intentionally introduced cracks, with and without 24 hour healing periods. The first test method involved electrochemical impedance spectroscopy (EIS) and the second test method is a novel in-situ electro-tensile test.

EIS is a non-destructive method often used to evaluate functional properties of organic coatings such as barrier, adhesion and active corrosion protection [41-43]. In recent years, the EIS technique has been successfully used to follow healing processes in extrinsic healing coatings using either encapsulation of two agents as in the work by Mehta et al. [44] or a single healing agent as employed by Garcia et al. [45, 46]. In the present work, EIS was employed to evaluate the potential of the CNT and non-CNT containing encapsulated 
systems to bridge and hence restore relatively big cracks. The restoration of the barrier properties in cracked coatings is as important as the restoration of the electrical conductivity.

As EIS does not provide information with respect to the recovery of the electrical conductivity and of the mechanical strength, an in-situ electro-tensile test was implemented to locally probe the restoration of electrical conductivity and the mechanical integrity at the healed damage. For this, a method was developed to assess self-healing via the controlled introduction of a crack into the coating by pulling it in tension under bright field optical microscopy while simultaneously measuring the change in electrical resistance. This method allows the assessment of electrical conductivity and elastic modulus of the coating.

\section{Materials and methods}

Figure 1 shows a sketch of the produced coatings and evaluation tests. The selection and processing of all materials and the characterization methods are described in following sections.

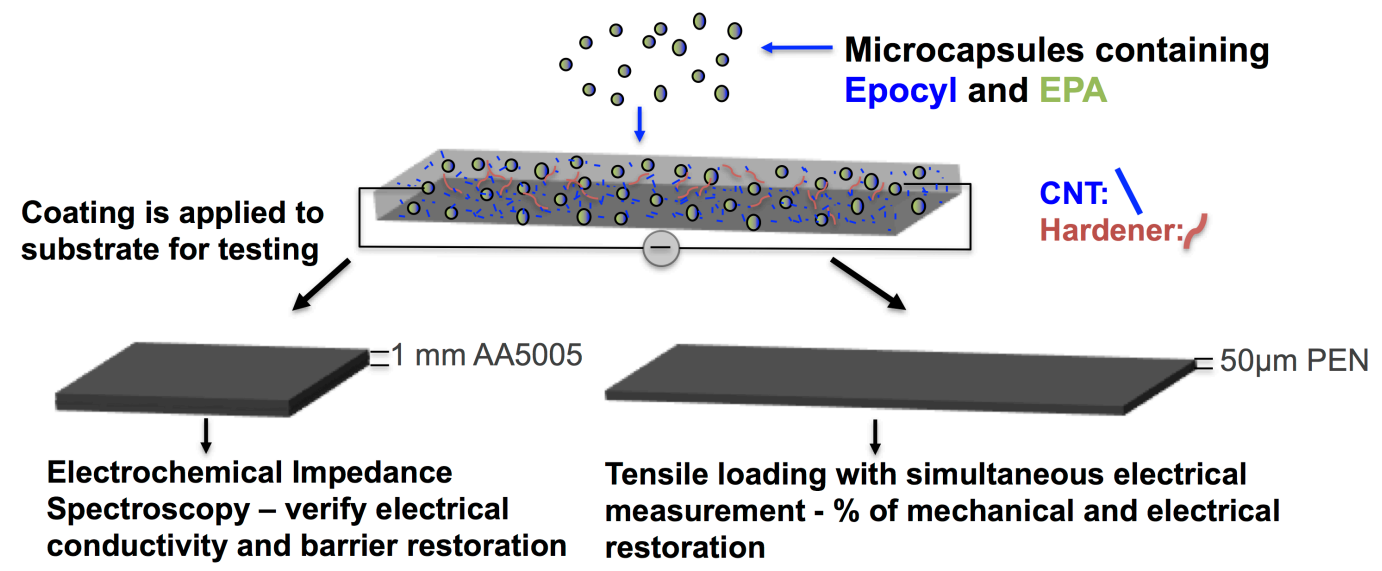

Figure 1. Sketch of the studied samples and evaluation tests.

\subsection{Materials}

The coating is intended for use in microelectronics, thus the material should be electrically conductive, mechanically stable, provide (chemo-) mechanical protection to the underlying component and possess a viscosity allowing for the formation of a thin coating, which cracks during tension without delamination. A bisphenol-A epoxy with a high concentration of CNTs $(\sim 20 \%)$ that provide electrical conductivity was chosen for the coating (ECNT, Epocyl ${ }^{\mathrm{TM}} \mathrm{NC}$ E128-02, Nanocyl). At room temperature, this resin has a viscosity of $400 \pm 50$ Pa.s. An epoxy without CNTs (EPON, Epikote $828 \mathrm{EL}$, Brenntag) was used as the epoxy matrix of control samples. The hardener, diethylenetriamine (DETA, Sigma Aldrich) was used to cure both epoxy resins at a concentration of $12.4 \mathrm{wt} \%$ as its high reactivity allows for crosslinking at room temperature.

All reagents for shell formulation, urea (Acros), resorcinol (Aldrich) and formaldehyde (Acros), as well as the acidic catalyst ammonium chloride (Fluka) and the ethylene maleic anhydride (EMA, Zeeland) surfactant were used in the as-received state. Hexyl acetate (HA, $99 \%$, Acros Organics) and ethyl phenyl acetate (EPA, 99\%, Sigma-Aldrich) were used as solvents. Two different substrate materials were also used, namely a $50 \mu \mathrm{m}$ thick polyethylene naphthalate foil (PEN, Teonex ${ }^{\circledR}$, Dupont-Teijin films, an insulating and transparent foil, which provides good bonding to the coating) for the electro-tensile tests and a $1 \mathrm{~mm}$ thick aluminum alloy (AA5005, Metallica Sàrl, a magnesium rich alloy exhibiting high mechanical properties and high resistance to corrosion) for the EIS tests. 


\subsection{Fabrication and processing methods}

A total of five different coating compositions, with and without microcapsules were fabricated as reported in Table 1 and detailed as follows.

Table 1: Summary of tested compositions (DETA concentration in all cases was $12.4 \mathrm{wt} \%$ ), and average initial electrical resistance values $\left(R_{0}\right)$.

\begin{tabular}{|c|c|c|c|c|}
\hline $\begin{array}{c}\text { Composition } \\
\#\end{array}$ & Purpose & $\begin{array}{c}\text { Microcapsule } \\
\text { Core } \\
\text { Composition }\end{array}$ & $\begin{array}{c}\text { Coating } \\
\text { Composition }\end{array}$ & $\begin{array}{c}\text { Average Initial } \\
\text { Resistance }\left(R_{0}\right) \\
{[\mathrm{M} \Omega]}\end{array}$ \\
\hline 1 & Mechanical and electrical healing & $\begin{array}{c}97.5 \mathrm{wt} \% \text { EPA : } \\
2.5 \mathrm{wt} \% \text { ECNT }\end{array}$ & $\begin{array}{c}\text { ECNT + } \\
\text { Microcapsules : } \\
\text { DETA }\end{array}$ & $0.86 \pm 0.12$ \\
\hline 2 & Mechanical healing & $\begin{array}{c}97.5 \mathrm{wt} \% \text { EPA : } \\
2.5 \mathrm{wt} \% \text { EPON }\end{array}$ & $\begin{array}{c}\text { ECNT + } \\
\text { Microcapsules : } \\
\text { DETA }\end{array}$ & $1.30 \pm 0.22$ \\
\hline 3 & $\begin{array}{c}\text { Control (EIS \& in-situ electro-tensile } \\
\text { loading) }- \text { effect of microcapsules } \\
\text { on coating properties }\end{array}$ & $\begin{array}{c}\text { ECNT + } \\
\text { Microcapsules : } \\
\text { DETA }\end{array}$ & $1.55 \pm 0.26$ \\
\hline 4 & $\begin{array}{c}\text { Control (EIS \& in-situ electro-tensile } \\
\text { loading) }\end{array}$ & $\begin{array}{c}\text { No } \\
\text { microcapsules }\end{array}$ & ECNT : DETA & $0.45 \pm 0.23$ \\
\hline 5 & $\begin{array}{c}\text { Control (EIS) - effect of conductive } \\
\text { capsule solution on impedance }\end{array}$ & $\begin{array}{c}\text { No } \\
\text { microcapsules }\end{array}$ & EPON : DETA & - \\
\hline
\end{tabular}

\subsubsection{Microcapsule preparation}

In this work, the oil-in-water emulsion technique of Blaiszik et al. was used for microencapsulation [47]. The encapsulated healing agent was a $97.5 \%: 2.5 \%$ (by weight) mixture of EPA and either ECNT (composition 1) or EPON (composition 2). The conductive ECNT was incorporated into microcapsules along with the 'healing solvent' EPA to improve not only healing efficiency in terms of mechanical properties, but electrical properties as well. Control samples were fabricated with microcapsules containing the 'non-healing' solvent HA (composition 3), which was found too nonpolar to demonstrate a solvent healing effect in an epoxy matrix [33], and without microcapsules (compositions 4 for ECNT and 5 for EPON).

In detail, $2.5 \mathrm{~g}$ of urea, $0.25 \mathrm{~g}$ of ammonium chloride and $0.25 \mathrm{~g}$ of ground resorcinol were dissolved in a mixture of $100 \mathrm{ml}$ of deionized water (DI) and $25 \mathrm{ml}$ of a $2.5 \mathrm{wt} \%$ EMA solution. The $\mathrm{pH}$ of the solution was then adjusted from approximately 2.7 to 3.5 using a $20 \%$ $\mathrm{NaOH}$ solution. The solution was subsequently stirred at a rate of $400 \mathrm{rpm}$ for a few minutes and $60 \mathrm{ml}$ of the core material followed by $6.33 \mathrm{~g}$ of formaldehyde were added allowing adequate mixing before each addition. The water bath temperature was then set to $55^{\circ} \mathrm{C}$ and the reaction was allowed to proceed for 4 hours. Afterwards, the microcapsules were left to cool down overnight and subsequently filtered and rinsed several times using DI water. After at least one day of drying under ambient conditions, the capsules were mechanically sieved, retaining only the microcapsule fraction between 125 and $250 \mu \mathrm{m}$ diameter.

\subsubsection{Coating fabrication}

For EIS testing, coating compositions 1 to 5 were applied to the aluminium substrate cut into rectangular pieces $(3 \times 4 \mathrm{~cm})$. The aluminium was first abraded with 2400 grit sandpaper and subsequently chemically etched with $2 \mathrm{M} \mathrm{NaOH}$. ECNT was mixed with $20 \mathrm{wt} \%$ microcapsules according to what type of healing was to be assessed, mixed well with DETA and degassed for $20 \mathrm{~min}$. The controls (i.e., containing no microcapsules) were fabricated by mixing either ECNT or EPON with DETA and similarly degassed for 20 min. All mixtures were applied on aluminium substrate using a Doctor Blade. The first 3 hours of curing at $25^{\circ} \mathrm{C}$ were under vacuum to prevent bubbles in the coatings. This was followed by 21 hours at $25^{\circ} \mathrm{C}$ and 24 hours at $35^{\circ} \mathrm{C}$ (not under vacuum). The final dry coating thickness was measured by calipers and found to be $0.22 \mathrm{~mm}( \pm 0.02)$ and $0.23 \mathrm{~mm}( \pm 0.03)$ for samples without and with microcapsules respectively 
For in-situ electro-tensile testing, coating compositions 1 to 4 were applied to the PEN substrate. Specifically, rectangular pieces $(15 \mathrm{~mm} \times 3 \mathrm{~mm})$ of PEN were cut and ionized with a corona pen for $5 \mathrm{~min}$. to improve bonding. The ECNT was mixed with capsules, DETA, degassed and applied as previously described. Finally, the films were cured at $25^{\circ} \mathrm{C}$ for 24 hours then post-cured at $35^{\circ} \mathrm{C}$ for an additional 24 hours and stored in a refrigerator at a temperature $<10^{\circ} \mathrm{C}$ to prevent further cross-linking and guarantee the presence of residual hardener in the coating. The final dry thickness of these coatings on PEN was found to be $0.23 \mathrm{~mm}( \pm 0.01)$ and $0.24 \mathrm{~mm}( \pm 0.01)$ for samples without and with microcapsules respectively.

\subsection{Characterization methods}

\subsubsection{Ethyl phenyl acetate and hexyl acetate uptake in ECNT and EPON}

The purpose of these tests was to determine if EPA is capable of diffusing into ECNT, increasing mobility of residual hardener and thus acting as a 'healing' solvent [35] and also verify that hexyl acetate (HA) was incapable of diffusing into (i.e. healing) ECNT. Cylindrical ECNT specimens $(9.7 \mathrm{~mm}$ diameter, $4.9 \mathrm{~mm}$ height) were fabricated using the same cure cycle as for coating fabrication and soaked in EPA or HA. Control samples fabricated with EPON and soaked in HA were used for comparison when examining the mass gain in HA; whereas, previous studies [35] were used for comparison regarding mass gain in EPA solvent. Each disc was weighed (dry mass: $M_{d}$ ) and subsequently placed in a sealed vial containing $20 \mathrm{ml}$ of EPA or HA for 24 hours at $25^{\circ} \mathrm{C}$. Discs were then removed, blotted with filter paper to remove solvent from the surface and weighed (wet mass: $M_{w}$ ). The mass gain is $\left(M_{w}-M_{d}\right) / M_{d}$. Measurements were made with a high-resolution precision balance (Mettler Toledo AT261 with $0.01 \mathrm{mg}$ accuracy) as a function of time until solvent uptake plateaued.

\subsubsection{Differential scanning calorimetry}

Differential scanning calorimetry (DSC) was used to determine polymer conversion over time in both dry (stored in desiccator with relative humidity $\mathrm{RH} \sim 20 \%$ ) and ambient (stored in open air with $\mathrm{RH} \sim 35-45 \%)$ conditions. DSC (TA Q100) tests were performed with a temperature ramp of $10^{\circ} \mathrm{C} / \mathrm{min}$ from $0^{\circ} \mathrm{C}$ to $200^{\circ} \mathrm{C}$ on ECNT samples of weight $5-10 \mathrm{mg}$. Prior to testing, the machine was equilibrated to $0^{\circ} \mathrm{C}$ followed by an isothermal process of $1 \mathrm{~min}$. The change in both the glass transition temperature $\left(T_{g}\right)$ and exothermic heat flow were tested each day over six days. Percentage of polymer conversion was calculated based on an average of three samples as $\left(1-\left(\Delta H_{\text {res }} / \Delta H_{\text {init }}\right)\right)^{*} 100$, where $\Delta H_{\text {res }}$ is the exothermic heat flow at a given time and $\Delta H_{\text {init }}$ is the exothermic heat flow value for uncured ECNT.

\subsubsection{Microscopy}

Optical microscopy was used to measure microcapsule dimensions in transmission mode with a 100X magnification (Olympus BX61). A small amount of microcapsules was deposited on a microscope slide and a drop of silicone oil added. Micrographs were processed using image analysis (analySIS pro) and 100 individual capsule diameter were measured with $1 \mu \mathrm{m}$ accuracy. Number mean diameter and volume mean diameter $\mathrm{D}[3,4][48]$ of these microcapsules were obtained, where:

$$
D[3,4]=\frac{\sum d_{i}^{4}}{\sum d_{i}^{3}}
$$

where $d_{i}$ is the diameter of capsule $i$. The number mean diameter is relevant regarding the probability of capsule cracking upon propagation of a crack in the medium, whereas the volume mean diameter is relevant in terms of delivery of healing agent. 
Scanning electron microscopy (SEM) was used to assess microcapsule morphology. A small amount of microcapsules containing $97.5 \mathrm{wt} \%$ EPA : $2.5 \mathrm{wt} \%$ ECNT were mounted on a stub using carbon tape. The capsules were then cross-sectioned with a razor blade, washed with acetone, and dried first with air then under vacuum for 2 hours. Microcapsules were carbon coated and viewed with a field emission SEM (FEI XL30-FEG SEM) using an accelerating voltage of $10.0 \mathrm{kV}$. Transmission Electron Microscopy (TEM) was employed to verify the non-clustering of the CNTs in the EPA. A small amount of EPA:ECNT microcapsules were pressed between two glass slides, separated, then dried under vacuum during 6 hours. The residual material was cured in epoxy on Teflon. TEM samples ( $80 \mathrm{~nm}$ thick) were cut with an ultramicrotome, placed on a mesh Cu grid, and imaged on a Philips/FEI CM12 TEM.

\subsubsection{Electrochemical impedance spectroscopy}

The EIS procedure followed the same approach as that previously described by Garcia et al. [46]. Three tests were performed: intact coating (intact), scratched (Scratch - T0), and scratched and healed for 24 hours (T24). The well-defined, $0.5 \mathrm{~mm}$ long scratches were performed with a micro-scratch tester (CSM Instruments SA, Switzerland) equipped with a $0.1 \mathrm{~mm}$ wide blade. In order to ensure that the aluminium substrate was reached, a progressive scan from 0 to $30 \mathrm{~N}$ was initially performed on all coatings. From this preliminary test, a $14 \mathrm{~N}$ load was determined necessary to penetrate to the underlying metal. Thus, the scratches for the EIS test (of $0.5 \mathrm{~mm}$ length) were subsequently performed at $14 \mathrm{~N}$ and $0.01 \mathrm{~mm} / \mathrm{min}$ rate. Immediately after scratching, the scratch was imaged with an optical microscope to obtain dimensions and verify that the cut extended to the metal substrate. Subsequently, EIS was performed to obtain the impedance signal for the scratched coating (Scratch - T0). The sample was then dismantled, dried and allowed further healing over a 24 hours period. After 24 hours, the scratch was again imaged to assess altered dimensions and verify whether the metal substrate remained visible. EIS (T24) testing representing the healed system immediately followed. T24 tests were repeated with specimens not exposed to the Scratch - T0 test in order to ensure that the first short immersion in electrolyte did not affect the healing process. In addition, two control tests were performed in which a small amount of the microcapsule healing solution was "manually added" to either an EPOCYL (Composition 4) or EPON (Composition 5) after scratching. This procedure demonstrated the highest possible healing efficiency and effect of the EPOCYL:EPA solution on EIS measurements respectively. For EIS testing, a PMMA tube with an inner radius of $2 \mathrm{~mm}$ equipped with an O-ring was clamped onto the coated aluminum and filled with $0.5 \mathrm{M} \mathrm{NaCl}$ (electrolyte) solution. EIS measurements were conducted using a three-electrode setup including a $\mathrm{Ag} / \mathrm{AgCl}$ reference electrode, a platinum mesh $(\sim 30 \mathrm{~mm}$ diameter $)$ counter electrode and the aluminum substrate as the working electrode. The EIS scans were performed over a frequency range of $10^{-2}$ to $10^{5} \mathrm{~Hz}$ using a sinusoidal amplitude of $5 \mathrm{mV}$ rms to the open circuit potential.

\subsubsection{In-situ electro-tensile testing}

The degree of mechanical and electrical self-healing efficiency was assessed via the introduction of a crack into the coating and subsequent evaluation of mechanical properties and electrical conductivity after 24 hours. The crack was introduced by applying a tensile load on the coating/substrate system at a nominal elongation rate of $1 \mu \mathrm{m} / \mathrm{s}$ with a miniature tensile stage (Linkam TSTE350 equipped with a $200 \mathrm{~N}$ load cell) and time, load, stress, and strain recorded. Electrical resistance $R$ was measured by gently abrading the two ends of the sample, positioning two electrodes at the abraded area, and applying fast drying silver paint. An Agilent 344101 multimeter and LabVIEW (National Instruments) program were used to record electrical resistance throughout the test. During tensile testing, the sample was situated under an optical microscope (Olympus BX60). The occurrence of (optically visible) cracks in the coating were identified as steps in the resistance measurement. Once cracking occurred, the tensile test was stopped, the sample unloaded to zero force, the crack imaged in bright field with 100X magnification, and crack dimensions obtained using analySIS pro software. The sample was then left in place for 24 hours at which point it was re-imaged and 
tested in an identical way. Normalized resistance $\Delta R / R_{0}$ (where $\Delta R=R-R_{0}$, and $R_{0}$ is the resistance of the unstrained sample) and stress were plotted vs. strain for the initial crack and after 24 hours and compared. The slopes (to $0.2 \%$ strain) of the stress-strain plots for three samples were used to calculate mechanical healing efficiency $\eta^{m}$ via:

$$
\eta^{m}=\frac{E_{\text {after 24 hours }}^{\text {coating }}-E_{\text {after 24 hours }}^{H A \text { control }}}{E_{\text {virgin }}^{\text {coating }}-E_{\text {after } 24 \text { hours }}^{H A \text { control }}}
$$

where $E_{\text {virgin }}^{\text {coating }}$ is the slope of the linear region of the virgin coating (i.e., before cracking),

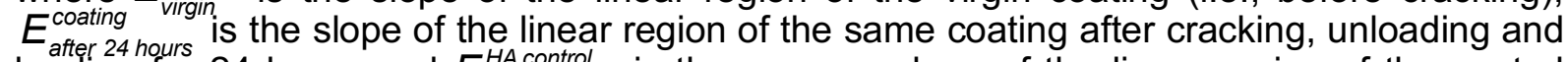
healing for 24 hours and $E_{\text {after } 24 \text { hours }}^{\text {HA }}$ is the average slope of the linear region of the control coating (i.e. sample contains HA capsules), again after cracking, unloading and healing for 24 hours.

The healing efficiency of electrical properties $\eta^{e}$ was assessed as:

$$
\eta^{e}=\frac{R_{0-24}}{R_{0-v}}
$$

where $R_{0-24}$ and $R_{0-v}$ are the average initial resistance of the coating of interest after 24 hours and the average initial resistance of the virgin coating (before cracking) based on three samples, respectively. Average values (based on three samples) for $R_{0}$ are given in Table 1 .

\section{Results and discussion}

\subsection{Ethyl phenyl acetate and hexyl acetate uptake in ECNT and EPON}

The ability of solvents to swell cured epoxy at RT is the first step in the proposed mechanism of solvent healing to decrease crack separation and bring the epoxy faces in close contact for chemical reactions across the interface to occur [32]. The ability of EPA to swell EPON and the corresponding healing of cracks in EPON over 24 hours has been shown by Neuser et al. [35], who correlated swelling and mass gain, since the EPA diffuses with a sharp profile characteristic of type II diffusion. Thus, diffusion kinetics of EPA by ECNT were compared to those of EPON. In comparison to EPON, ECNT exhibited a faster initial absorption of EPA, but saturated at a lower mass gain of approximately $3 \%$ (Figure 2a).

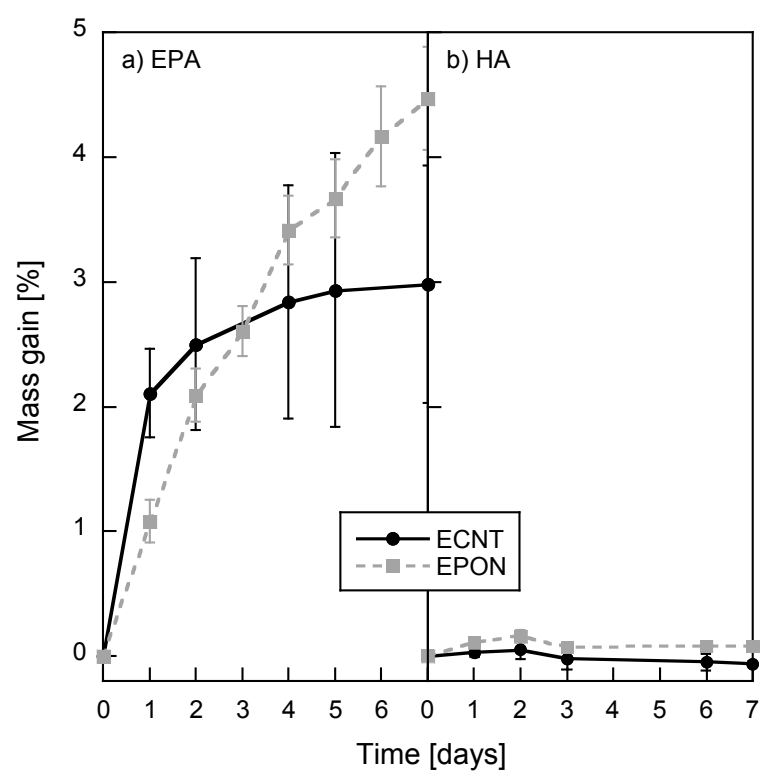

Figure 2. ECNT and EPON mass gain in EPA (a) and HA (b) at room temperature over 1 week. 
From these observations, it can be said that EPA increased chain mobility in ECNT and thus acted as a healing solvent similar to EPON. The rapid mass gain demonstrated by ECNT in the first 24 hours was ideal as self-healing was assessed within the first 24 hours for this study. Figure $2 \mathrm{~b}$ demonstrates that HA is incapable of swelling both ECNT and EPON and behaves as a "non-healing" control.

\subsection{Epoxy conversion and glass transition temperature}

The variation in the degree of polymer chain conversion as a function of time is shown in Figure 3 . The initial cure for 24 hours at $25^{\circ} \mathrm{C}$ resulted in a $71 \%$ conversion of polymer and increased to $75 \%$ after the post-cure for 24 hours at $35^{\circ} \mathrm{C}$. Following the cure and post-cure, coatings were kept either in a desiccator with a measured $\mathrm{RH}$ of $20 \%$ at $25^{\circ} \mathrm{C}$ or ambient conditions ( $\mathrm{RH} \sim 35-45 \%$ ) to establish the effect of humidity on ECNT cure as it was probable that humidity would influence the epoxy cure [49-51]. The subset graph in Figure 3 reveals a slight decrease in the percent of polymer chains converted when the sample was left in ambient conditions. Conversion after the post-cure was similar to that obtained with other epoxies for solvent healing [34]. Glass transition temperature $\left(T_{g}\right)$ was also measured with DSC. The $T_{g}$ for uncured epoxy was below RT and is not shown in the figure. As the curing reaction progresses, polymer chain mobility decreases resulting in an increase in the $T_{g}$ [52]. This was the case for ECNT where the $T_{g}$ increased from approximately $53^{\circ} \mathrm{C}$ to $60^{\circ} \mathrm{C}$ for the cure and post-cure (Figure 3 - Day 1 to 2) state respectively. Within one week, the $\mathrm{T}_{\mathrm{g}}$ increased another $4^{\circ} \mathrm{C}$ at $20 \% \mathrm{RH}$ and $2^{\circ} \mathrm{C}$ in ambient conditions (RH $\left.\sim 35-45 \%\right)$. The effect of humidity is more apparent concerning the $T_{g}$. The decrease in $T_{g}$ in a more humid environment is due to absorbed water acting as a plasticizer during the curing process [53]. Figure 3 shows continued polymer conversion after the post-cure, thus the cure cycle utilized herein does result in an 'under-cured' matrix dependent at the time of testing. An under-cured system is necessary as increased cure of the epoxy matrix (i.e. increased conversion of hardener) results in a decrease in swelling and residual hardener within the matrix and thus a decrease in healing efficiency upon cracking [54]. The room temperature cure cycle utilized herein is beneficial as it permits the study of microcapsule based healing within ECNT on a more relevant time-scale and without external stimuli; however, storage below RT or immediate use of the coatings is necessary in this model system to retain hardener and inhibit premature curing within the ECNT matrix.

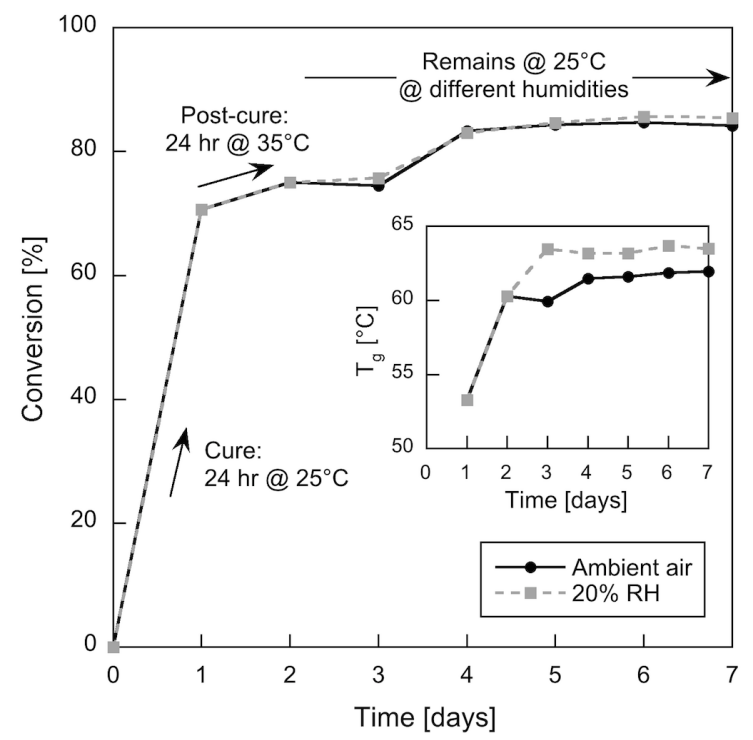

Figure 3. Percent conversion of polymer chains and corresponding $T_{g}$ over 1 week in ambient air (RH 35-45\%) and under $20 \% \mathrm{RH}$. 


\subsection{Microencapsulation of self-healing solutions}

Figure 4 reveals the morphology and size distribution respectively of microcapsules. The size distribution has the usual log-normal distribution [55]. The average diameter and volume mean diameter were calculated (Table 2). The microcapsules had similar average diameters $(\sim 170 \mu \mathrm{m})$ and analogous volume mean diameters $(\sim 180 \mu \mathrm{m})$ and thus contained similar amounts of core material.
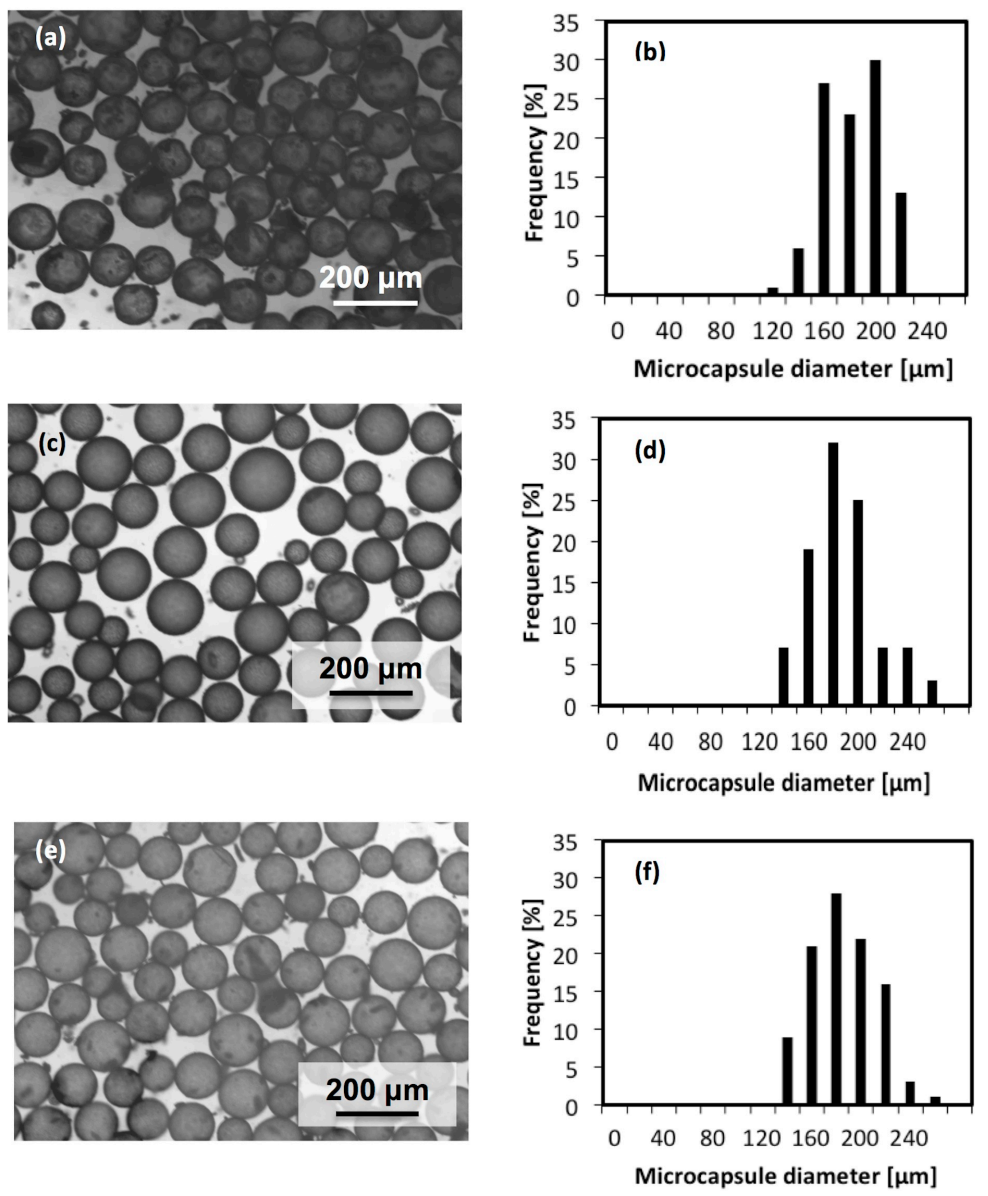

Figure 4. Optical microscopy images of microcapsules (left) containing EPA and ECNT (a), EPA and EPON (c), and HA (e) and size distributions (right) of microcapsules containing EPA and ECNT (b), $E P A$ and $E P O N(d)$, and $H A(f)$.

Table 2. Average microcapsule diameter obtained at a stirring rate of $400 \mathrm{rpm}$.

\begin{tabular}{|l|c|c|}
\hline Microcapsules $(125-250 \mu \mathrm{m})$ & $\begin{array}{c}\text { Number mean } \\
\text { diameter }(\mu \mathrm{m})\end{array}$ & $\begin{array}{c}\text { Volume mean } \\
\text { diameter }(\mu \mathrm{m})\end{array}$ \\
\hline $97.5 \mathrm{wt} \%$ EPA : 2.5 wt\% ECNT & 173.0 & 181.9 \\
\hline $97.5 \mathrm{wt} \%$ EPA : $2.5 \mathrm{wt} \%$ EPON & 177.1 & 190.2 \\
\hline $100 \mathrm{wt} \% \mathrm{HA}$ & 176.4 & 187.3 \\
\hline
\end{tabular}

Figure 5a displays a cross-sectioned microcapsule and reveals a spherical capsule with a rough exterior and smooth interior. Figure $5 \mathrm{~b}$ reveals a more detailed view of the inner surface that is in contact with the healing solvent (EPA:ECNT). This smooth, non-porous surface is important as it minimizes mass transport of the core material through the microcapsule shell. Thus, the encapsulated healing agent will be relatively well contained in 
the microcapsule until damage occurs. On the contrary, the microcapsule outer surface (Figure 5c) is rough due to agglomeration of UF nanoparticles [56]. This rough outer surface improves adhesion of the microcapsule to the thermosetting matrix.
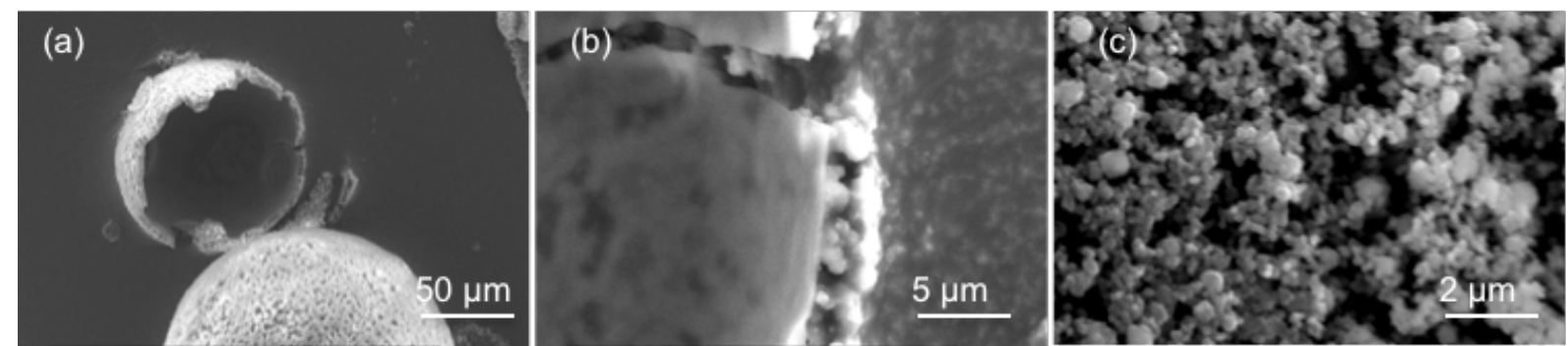

Figure 5. SEM images of (a) a broken capsule (b) microcapsule interior and (c) microcapsule exterior.

TEM imaging of crushed capsules containing EPA and ECNT demonstrated the homogeneous non-clustered state of the incorporated CNTs (Figure 6). Despite the presence of various aggregates, it is evident that CNTs were dispersed within the healing agent.

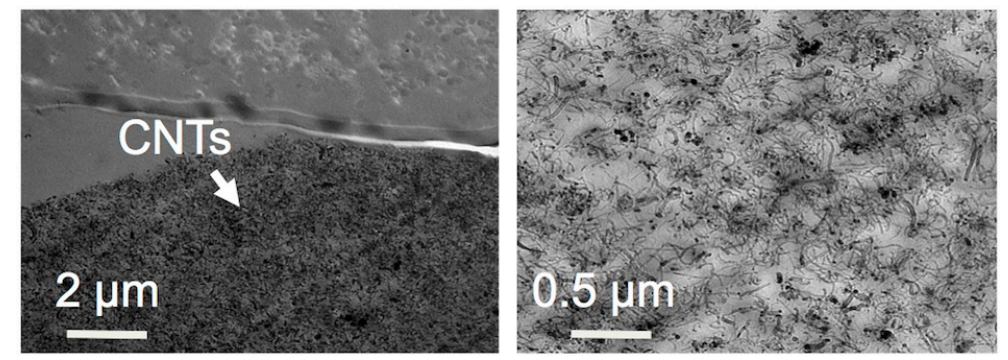

Figure 6. TEM imaging of CNT encapsulation and distribution within microcapsule.

\subsection{Electrochemical impedance spectroscopy}

Figure 7 shows the impedance modulus variation with the frequency obtained from the EIS tests for the ECNT coating containing HA capsules (Figure 7a), EPA-EPON capsules (Figure 7b) and EPA-ECNT capsules (Figure 7c). All coatings reveal a similar capacitive behavior when intact (high $|Z|$ and straight line evolution). When damaged, the impedance of each coating decreases significantly (Scratch - T0) indicating a loss of barrier properties as the electrolyte now reaches the underlying metal allowing a better ionic conduction and thus lower resistance to flow. After 24 hours, the three systems show different behaviors. While the ECNT coating containing microcapsules with an EPA-ECNT core shows full restoration of the impedance (Figure 7c), the ECNT coating with EPA-EPON filled microcapsules only shows a partial restoration (Figure $7 \mathrm{~b}$ ) and the ECNT coating with HA filled microcapsules shows absolutely no effect on the impedance (Figure 7a). On the other hand as can be deduced from the significant increase in the low frequency impedance values, the coatings containing EPA:ECNT, and, to a lower extent, the EPA:EPON system showed a partial or full restoration of the barrier properties after 24 hours healing time. It should be noted that the trends observed in terms of barrier restoration are the same as those observed in tests in which the healing agent was added manually, showing that the efficiency increased in the order EPA-ECNT > EPA-EPON > HA; such results suggest the significant role played by the $\mathrm{CNT}$ in the restoration of the local barrier protection. 

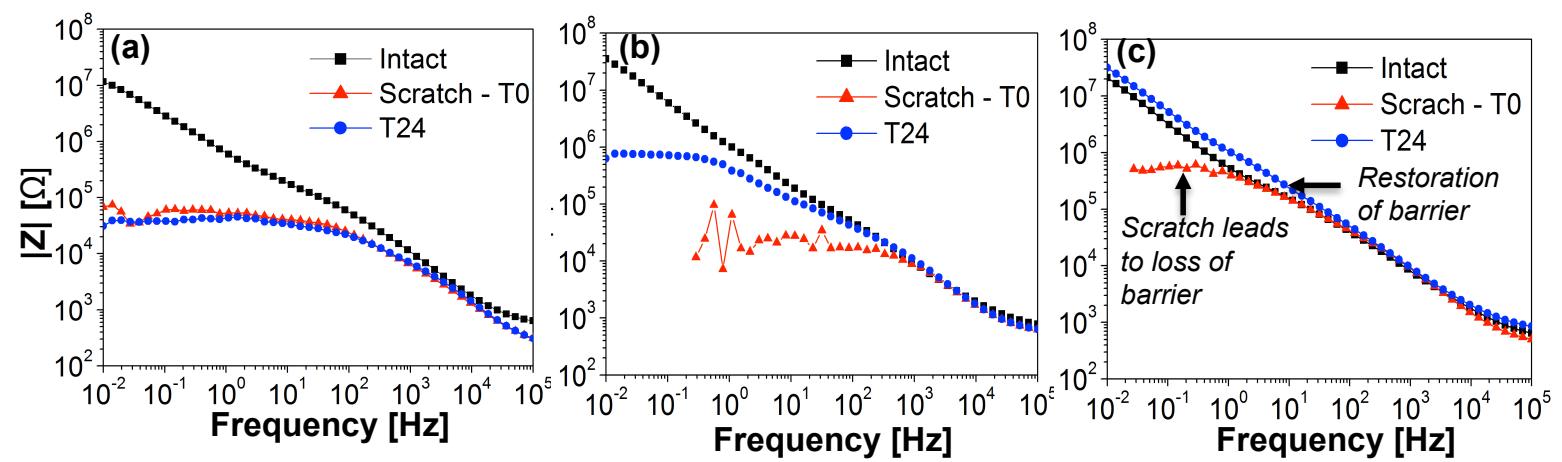

Figure 7. Impedance modulus vs. frequency spectra for ECNT coatings containing microcapsules filled with (a) $H A$, (b) EPA:EPON, and (c) EPA:ECNT, the latter being the only coating able to restore its barrier properties after the 24 hours healing time.

\subsection{In-situ electro-tensile loading}

The stress and normalized electrical resistance $\Delta R / R_{0}$ vs. strain for the control ECNT sample without microcapsules (Composition 4) is displayed in Figure 8a. The virgin coating cracked at a strain near $3 \%$ and at a maximum stress of $28 \mathrm{MPa}$. The $5 \%$ increase in resistance corresponded to a strain gage effect and 'infinite' resistance (i.e., the ohmmeter was out-ofrange) corresponded to a crack in the coating. The slope of the stress-strain after 24 hours was much lower than that of the virgin stress-strain curve indicating the absence of restoration of mechanical properties. The apparent slope is due only to the undamaged PEN substrate. Also, the electrical resistance remained at infinity after 24 hours, revealing no healing of electrical conductivity. These results were expected as no microcapsules and thus no method of self-healing was incorporated into the film. This sample was used as a control to validate the method used herein.

Figure $8 \mathrm{~b}$ shows the stress and normalized electrical resistance vs. strain for the control sample containing HA filled microcapsules (Composition 3) in which no healing was expected. This sample was used as a reference indicating the influence of microcapsules on virgin properties of the coating. The virgin maximal stress of the coating decreased from $28 \mathrm{MPa}$ to $18.5 \mathrm{MPa}$ upon the incorporation of microcapsules. The presence of $\sim 25 \mathrm{vol} \%$ microcapsules in the matrix can be viewed as heterogeneities within the matrix, reducing the coating's tensile modulus and its failure stress. Figure $8 \mathrm{~b}$ reveals an increased maximum stress after 24 hours compared to that of the virgin test. This is counterintuitive since the epoxy conversion (Figure 3 ) remained constant between day 2 (when the samples were first tested) and day 3 (after 24 hours healing). A possible explanation could be the partition of the stress between the coating and the substrate. It could also result from the long linear carbon chain and apolarity of HA allowing for enhanced absorption into PEN, consequently increasing polymer plasticity [57]. As with the coating of pure ECNT (i.e. containing no microcapsules) the Young's modulus after 24 hours was much lower than the virgin stress and electrical resistance was infinite. This indicates that there was no healing of mechanical properties or electrical conductivity.

Figure $8 \mathrm{c}$ shows the results for coatings containing 20wt\% EPA:EPON microcapsules (Composition 2). Contrasting the aforementioned tests, Figure $8 \mathrm{c}$ reveals analogous slopes for the virgin stress-strain curve and stress-strain curve after 24 hours, implying restoration of mechanical properties during the 24 hours period. However, the normalized electrical resistance after 24 hours still increases quite precipitously at the beginning of the test resembling the trend seen in the previous coatings more closely than that of the following Figure 8d. From this one can conclude that only a slight amount of healing in terms of electrical conductivity occurred within the 24 hours period, perhaps, as a result of the rejoining of the two interfaces. 
Figure $8 \mathrm{~d}$ displays the outcome for coatings fabricated with $20 \mathrm{wt} \%$ EPA:ECNT microcapsules (Composition 1). Similar to Figure 8c, the modulus after 24 hours was nearly identical to that of the virgin modulus, signifying restoration of mechanical properties. Contrary to the previous three coatings, the normalized electrical resistance after 24 hours is not infinite, denoting measurable electrical conductivity up to the cracking strain of $2.2 \%$ and partial restoration of electrical properties. In addition, the coating is capable of sufficient charge transfer while locally cracking as seen by the stepwise nature in the virgin $\Delta R / R_{0}$ curve. Another interesting aspect of the data represented in Figure $8 \mathrm{~d}$ is the loss in electrical resistance at $\sim 2 \%$ strain in the $\Delta R / R_{0}$ curve after 24 hours which mimics the result shown for the virgin $\Delta R / R_{0}$ curve in Figure $8 \mathrm{a}$. The similarity of these values reflects crack restoration analogous to pure ECNT (Composition 4).
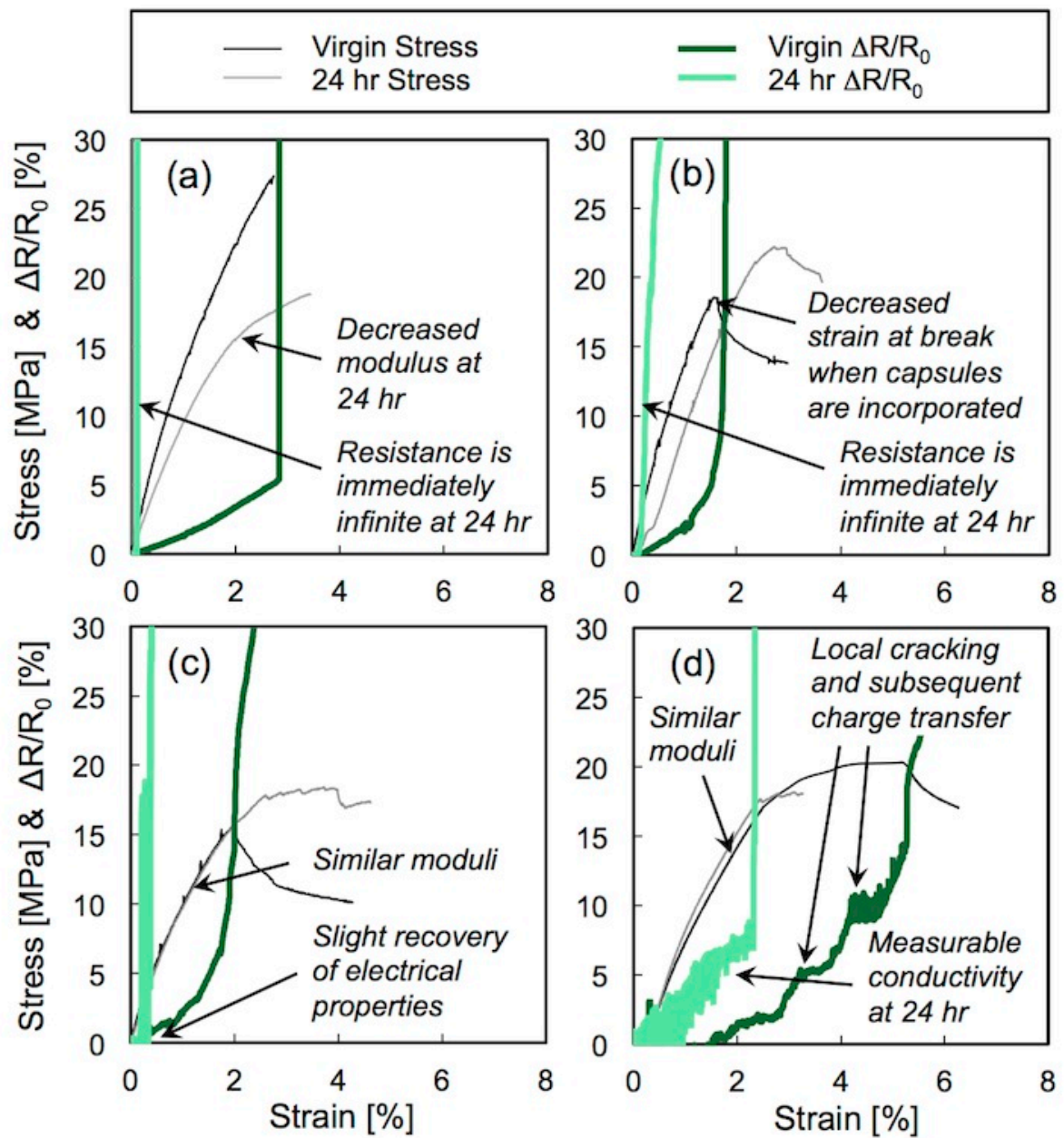

Figure 8. Stress and normalized electrical resistance of an ECNT coating (a) without capsules, with (b) hexyl acetate capsules, (c) EPA:EPON microcapsules, and (d) EPA:ECNT - The only coating capable of restoring both mechanical properties and electrical conductivity. Plot (d) shows multiple loss and recovery events of the electrical properties.

\subsection{Extent of mechanical and electrical conductivity restoration}

Table 3 displays healing efficiency values for the different coatings obtained via in-situ electro-tensile loading. Coatings containing no capsules or capsules of HA had mechanical and electrical efficiencies equal to 0 within experimental scatter, indicating no healing and providing controls for the study. For coatings with EPA:ECNT or EPA:EPON microcapsules incorporated, the mechanical efficiency was $81 \%( \pm 39)$ or $72 \%( \pm 29)$ respectively.

There is a clear trend when considering the healing efficiency of electrical properties. Electrical healing efficiency increased from $1.9 \%$ to $50 \%$ when microcapsules containing healing solvent and EPON were incorporated into the coating, and further to $64 \%$ in the case 
of EPA:ECNT capsules. The fact that the control coatings containing no microcapsules or those containing HA-filled microcapsules showed a non-zero change in electrical resistance is attributed to weak mechanical contact between the crack faces upon release of the tension. The higher value for the coating containing HA microcapsules compared to that of the coating with no microcapsules could result from a difference in the intersection of the crack faces after tension is released. This difference could result from either the incorporation of microcapsules increasing coating ductility or an effect of HA on the plasticity of PEN. This data reveals that incorporated microcapsules are able to open upon crack propagation and initiate healing when EPA and either ECNT or EPON is encapsulated. Also, as was predicted, the encapsulation of additional carbon nanotubes improved the healing of electrical conductivity in addition to restoring barrier and mechanical properties.

Table 3. Mechanical and electrical efficiency of different ECNT coatings.

\begin{tabular}{|l|c|c|}
\hline Microcapsule core composition & Mechanical Efficiency (\%) & Electrical Efficiency (\%) \\
\hline EPA:ECNT & $81 \pm 39$ & $64 \pm 23$ \\
\hline EPA:EPON & $72 \pm 29$ & $50 \pm 6.9$ \\
\hline HA & $-4 \pm 14$ & $6.2 \pm 6.9$ \\
\hline No microcapsules & - & $1.9 \pm 2.3$ \\
\hline
\end{tabular}

Figures $9 a$ and $9 \mathrm{~b}$ show optical micrographs for virgin and healed cracks respectively for a sample of pure ECNT (composition 4) on PEN where the crack is still present after 24 hours with an unchanged width of 2-3 $\mu \mathrm{m}$. Similar results were seen when HA capsules were incorporated into the film. However, this was not the case when $20 \mathrm{wt} \%$ microcapsules
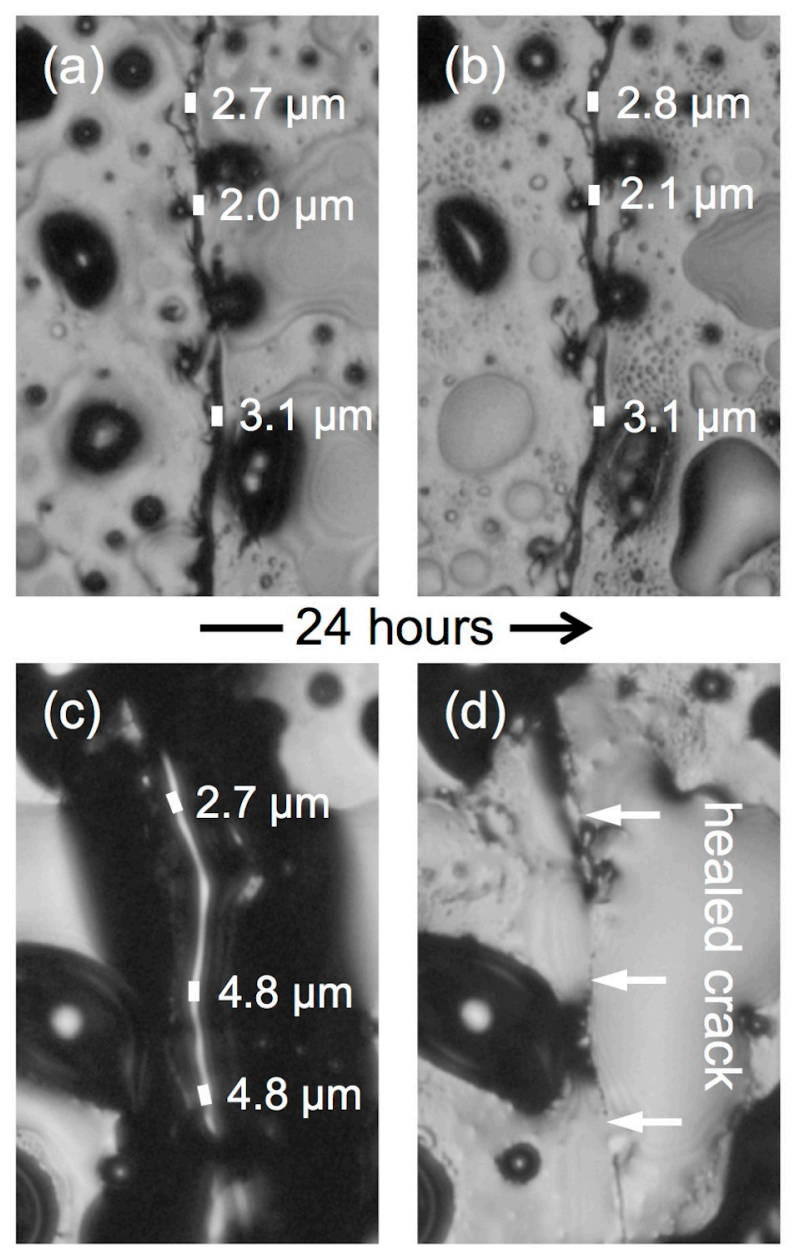

Figure 9. Optical micrographs of a crack in a coating of ECNT without microcapsules immediately after cracking (a) and after 24 hours (b) and in a coating of ECNT with microcapsules containing EPA:ECNT immediately after cracking (c) and after 24 hours (d). Crack width values are shown in the micrographs. 
containing EPA and ECNT were incorporated into the coating (composition 1). Herein, a crack with even slightly larger dimensions (3-5 $\mu \mathrm{m}$, Figure 9c) than the crack in pure ECNT (with no capsules) heals to an immeasurable crack width (Figure 9d). Similar results were visualized for coatings containing EPA:EPON microcapsules. It should be noted that, in spite of a limited depth of field, the $\sim 0.2 \mu \mathrm{m}$ resolution of the optical microscope was adequate enough to detect crack closure. The reported mechanical and electrical healing efficiencies were obtained using the in-situ electro-tensile method, in which rather long and narrow cracks (width of several $\mu \mathrm{m}$ ) propagate across the width of the coating. In contrast, EIS testing allowed for very consistently dimensioned scratches of much larger dimensions (width: $0.1 \mathrm{~mm}$; length: $0.5 \mathrm{~mm}$ ) and thus provided a complementary method to accurately analyze the consistency and limit of crack healing.

\section{Conclusions}

Two different self-healing coatings and two controls based on an electrically conductive epoxy resin with approximately $20 \%$ CNTs were fabricated herein. The ability to encapsulate this electrically conductive epoxy (ECNT) with EPA was demonstrated. These coatings are model systems and allow for the study of solvent-based microcapsule self-healing in electrically conductive coatings. In addition to novel fabrication methods, two methods were developed to assess self-healing via the controlled introduction of cracks into the coating, with and without 24 hours healing periods. EIS testing confirmed that coatings possessing microcapsules with an EPA:ECNT or EPA:EPON core lead to improved barrier restoration. Full restoration of barrier properties was only possible with microcapsules containing ECNT (i.e. containing CNTs). As no information could be obtained from EIS with respect to the extent of electrical conductivity or mechanical restoration, a novel in-situ electro-tensile test was subsequently introduced. For this, a method was developed to assess self-healing via the controlled introduction of a crack by pulling the coating in tension while simultaneously measuring the change in electrical resistance. Complementing the EIS results, it was demonstrated that when microcapsules possessing an EPA:ECNT core were incorporated into the coating, electrical conductivity and mechanical properties were restored to $64 \%( \pm 23)$ and $81 \%( \pm 39)$ respectively. Furthermore, sequential cracking and healing events were noticed while the coating was pulled in tension and both EIS and in-situ tensile loading and electrical conductivity test revealed a 24 hours restoration of this coating analogous to pure ECNT. Optical microscopy images immediately and 24 hours after cracking confirmed the healing in ECNT coatings containing EPA:ECNT filled microcapsules and a lack of healing when no microcapsules were incorporated.

\section{Acknowledgements}

Funding from the European Union Seventh Framework Programme [FP7/2007-2013] under grant agreement $n^{\circ} 290308$ (Marie Curie ITN SHeMat 'Self-Healing Materials: from Concepts to Market') is gratefully acknowledged. The EPFL Interdisciplinary Center for Electron Microscopy is acknowledged for technical support with the SEM and TEM analyses. Mina Abdolahzadeh (TU Delft), Ranjita Bose (TU Delft) and Bastien Le Gars Santoni (EFPL) are additionally acknowledged for assisting with EIS setup, CSM micro-scratch tester setup and electro-tensile testing respectively.

\section{References}

1. Wool, R.P., Polymer Interfaces: Structure and Strength. 1995, New York: Hanser Press.

2. Talreja, R., Damage mechanics of composite materials. 1994, Amsterdam: Elsevier.

3. Bergman, S.D. and F. Wudl, Mendable polymers. J. Mater. Chem., 2008. 18: p. 4162.

4. Zang, M.Q., Self healing in polymers and polymer composites. Concepts, realization and outlook: A review. Polymer Letters, 2008. 4: p. 238-250. 
5. Aïssa, B., et al., Self-healing materials systems: Overview of major approaches and recent developed technologies. Adv. Mater. Sci. Eng., 2012. 2012.

6. Li, Y., K.-S. Moon, and C.P. Wong, Nano-conductive adhesives for nano-electronics interconnection, in Nano-bio-electronic, Photonic and MEMS Packaging. 2010, Springer. p. 19-45.

7. May, C.A., Epoxy resins: Chemistry and technology. 2 ed. 1988, New York: Marcel Dekker Inc.

8. Blaiszik, B.J., et al., Self-healing polymers and composites. Annu. Rev. Mater. Res., 2010. 40: p. 179-211.

9. Varghese, S., A. Lele, and R. Mashelkar, Metal ion mediated healing of gels. J. Polym. Sci. Part A - Polym. Chem., 2006. 44: p. 666-670.

10. Bhushan, B., Biomimetics: Lessons from nature-an overview. Phil. Trans. Roy. Soc., 2009. 367: p. 1445-1486.

11. Trask, R.S., H.R. Williams, and I.P. Bond, Self-healing polymer composites: mimicking nature to enhance performance. Bioinspiration \& Biomimetics, 2007. 2: p. 1-9.

12. Benson, R.C., D. Farrar, and J.A. Miragliotta, Polymer adhesives and encapsulants for microelectronic applications. Johns Hopkins APL Technical Digest, 2008. 28: p. 58-71.

13. Wolfson, H. and G. Elliot, Electrically conducting cements containing epoxy resins and silver. US2774747 patent, 1956.

14. Matz, K.R., Electrically conductive cement and brush shunt connection containing the same. US2849631 patent, 1958.

15. $\quad$ Beck, D.P., Printed electrical resistors. US2866057 patent, 1958.

16. Li, Y., K. Moon, and C.P. Wong, Electronics without lead. Science, 2005. 308: p. 1419-1420.

17. Santamaria, A., et al., Electrically conductive adhesives with a focus on adhesives that contain carbon nanotubes. J. Appl. Polym. Sci., 2013. 129: p. 1643-1652.

18. Eitner, U., et al., Characterization of electrically conductive adhesives. Energy Proceed., 2012. 27: p. 676.

19. Yim, M.J., W. Kwon, and K.W. Paik, Effect of filler content on the dielectric properties of anisotropic conductive adhesive materials for high-frequency flip-chip interconnection. Mater. Sci. Eng. Part B 2006. 126: p. 59-65.

20. Kwon, Y., et al., Dispersion, hybrid interconnection and heat dissipation properties of functionalized carbon nanotubes in epoxy composites for electrically conductive adhesives (ECAs). Microelectron. Reliab., 2011. 51: p. 812-818.

21. Ma, P.C., B.Z. Tang, and J.K. Kim, Effect of CNT decoration with silver nanoparticles on electrical conductivity of CNT-polymer composites. Carbon, 2008. 46: p. 14971505.

22. Tang, X., et al. Carbon nanotube enhanced thermally and electrically conductive adhesive for advanced packaging. in 2010 11th International Conference on Electronic Packaging Technology and High Density Packaging (ICEPT-HDP) 2010. Big Sky, MT: IEEE.

23. Chen, X., et al., Mechanical and thermal properties of epoxy nanocomposites reinforced with amino-functionalized multi-walled carbon nanotubes. Mater. Sci. Eng. A, 2008. 492: p. 236-242.

24. Zhu, J., et al., Reinforcing epoxy polymer composites through covalent integration of functionalized nanotubes. Adv. Funct. Mater., 2004. 14: p. 643-648.

25. White, S.R., et al., Autonomic healing of polymer composites. Nature, 2000. 409: p. 794-797.

26. Schmets, A.J.M. and S. van der Zwaag. Proceedings of the first international conference on self healing materials. in Supplement to Springer series in materials science. 2007. Noordwijk, Netherlands.

27. Neuser, S., et al., Fracture toughness healing in epoxy containing both epoxy and amine loaded capsules. Adv. Eng. Mater., 2014. 16: p. 581-587.

28. Yuan, Y.C., et al., Self-healing polymeric materials using epoxy/mercaptan as the healant. Macromolecules, 2008. 41: p. 5197-5202. 
29. Lee, J., et al., Fracture behavior of a self-healing microcapsule-loaded epoxy system. eXPRESS Polymer Letters, 2011. 5: p. 246-253.

30. Samadzadeh, M., et al., A review on self-healing coatings based on micro/nanocapsules. Prog. Org. Coat., 2010. 68: p. 159-164.

31. Jin, H., et al., Fracture behavior of a self-healing, toughened epoxy adhesive. Int. J. Adhes. Adhes. , 2013. 44: p. 157-165.

32. Caruso, M.M., et al., Solvent-promoted self-healing epoxy materials. Macromolecules, 2007. 40: p. 8830-8832.

33. Caruso, M.M., et al., Full recovery of fracture toughness using a nontoxic solventbased self-healing system. Adv. Funct. Mater., 2008. 18: p. 1898-1904.

34. Neuser, S. and V. Michaud, Effect of aging on the performance of solvent-based selfhealing materials. Polym. Chem., 2013. 4: p. 4993-4999.

35. Neuser, S., V. Michaud, and S.R. White, Improving-solvent based self-healing materials through shape memory alloys. Polymer, 2012. 53: p. 370-378.

36. Miller-Chou, B.A. and J.L. Koenig, A review of polymer dissolution. Prog. Polym. Sci., 2003. 28: p. 1223-1270.

37. Neuser, S. and V. Michaud, Fatigue response of solvent-based self-healing smart materials. Experimental Mechanics, 2014. 54: p. 293-304.

38. Neuser, S., E. Manfredi, and V. Michaud, Characterization of solvent-filled polyurethane/urea-formaldehyde core-shell composites. Mater. Chem. and Phys., 2014. 143: p. 1018-1025.

39. Blaiszik, B.J., et al., Autonomic restoration of electrical conductivity. Adv. Mater., 2011. 24: p. 398-401.

40. Kang, S., et al., Microencapsulated carbon black suspensions for restoration of electrical conductivity. Adv. Funct. Mater., 2014. 24: p. 2947-2956.

41. Bierwagen, G.P., Critical pigment volume concentration (CPVC) as a transition point in the properties of coatings. J. Coat. Technol., 1992. 64: p. 71-75.

42. Skerry, B.S., C.J. Chen, and C.J. Ray, Pigment volume concentration and its effect on the corrosion resistance properties of organic paint films. J. Coat. Technol., 1992. 64: p. 77-86.

43. van Westing, E.P.M., G.M. Ferrari, and J.H.W. de Wit, The determination of coating performance with impedance measurements - I. Coating polymer properties. Corros. Sci., 1993. 34: p. 1511-1530.

44. Mehta, N.K. and M.N. Bogere, Environmental studies of smart/self-healing coating system for steel. Prog. Org. Coat., 2009. 64: p. 419-428.

45. Garcia, S.J., et al., Self-healing anticorrosive organic coating based on an encapsulated water reactive silyl ester: Synthesis and proof of concept. Prog. Org. Coat., 2011. 70: p. 142-149.

46. Garcia, S.J., X. Wu, and S. van der Zwaag, A combined EIS and X-ray computed tomography study of the effect of a silyl ester on delamination and underfilm pit formation in a coated AA7050 sample. Corrosion, 2014. 70: p. 475-482.

47. Blaiszik, B.J., et al., Microcapsules filled with reactive solutions for self-healing materials. Polymer, 2009. 50: p. 990-997.

48. Horiba Instruments, I., A Guidebook to Particle Size Analysis. 2012: p. 1-30.

49. Hartwig, A., B. Schneider, and A. Lühring, Influence of moisture on the photochemically induced polymerisation of epoxy groups in different chemical environment. Polymer, 2002. 43: p. 4243-4250.

50. Esposito Corcione, C., et al., UV-curable epoxy systems containing hyperbranched polymers: Kinetics investigation by photo-DSC and real-time FT-IR experiments Polym. Test., 2009. 28: p. 157-164.

51. Cai, Y. and J.L.P. Jessop, Effect of water concentration on photopolymerized acrylate/epoxide hybrid polymer coatings as demonstrated by Raman spectroscopy. Polymer, 2009. 50: p. 5406-5413.

52. Min, B.-G., Z.H. Stachurski, and J.H. Hodgkin, Cure kinetics of elementary reactions of a DGEBA/DDS epoxy resin: 1. Glass transition temperature versus conversion. Polymer, 1993. 34: p. 4908-4912. 
53. Lampman, S., Characterization and failure analysis of plastics. 2003: ASM International. 489.

54. Neuser, S., Tailored capsule based self-healing for epoxy matrix composites, PhD thesis \#5978, École Polytechnique Fédérale de Lausanne: Suisse. p. 148.

55. Haussonne, J.-M., et al., Céramiques et verres: Principes et techniques d'elaboration. Traité des matériaux 16. 2005: PPUR, Lausanne. 64.

56. Brown, E.N., et al., In situ poly(urea-formaldehyde) microencapsulation of dicyclopentadiene. J. Microencapsulation, 2003. 20: p. 719-730.

57. van Willige, R., et al., Influence of storage time and temperature on absorption of flavor compounds from solutions by plastic packaging materials. J. Food Sci., 2002. 67: p. 2023-2031. 